\title{
Attitudes towards Study Effort Response to Higher Grading Standards: Do Gender and Personality Distinctions Matter?
}

\author{
Lars Fallan $^{1} \&$ Leiv Opstad ${ }^{1}$ \\ ${ }^{1}$ Trondheim Business School, Trondheim, Norway \\ Correspondence: Lars Fallan, Trondheim Business School, N-7004 Trondheim, Norway. Tel: 47-73-559-969. \\ E-mail: lars.fallan@toh.hist.no
}

Received: June 6, 2012

Accepted: September 4, $2012 \quad$ Online Published: October 15, 2012

doi:10.5539/jel.v1n2p179

URL: http://dx.doi.org/10.5539/jel.v1n2p179

\begin{abstract}
The purpose of this paper is to explore how gender and personality preferences affect student attitudes towards effort response to higher grading standards.

Data collected from 150 economics and business students at a Scandinavian business school reveals that higher grading standards enhance effort and time devoted to learning to a higher degree among male than female students. Furthermore, personality dimensions from Myer-Briggs Type Indicator (MBTI) indicate that students having extrovert, thinking and judging preferences respectively do respond more positively towards a harder grading practice, compared to those who have introvert, feeling and perceiving preferences, respectively.

Further research is needed to see whether these findings are readily generalized, or whether they should be interpreted in light of Scandinavian culture and business school settings.
\end{abstract}

Keywords: grading standards, study effort, gender, MBTI

\section{Introduction}

\subsection{Effort Response to Higher Grading Standards}

Many studies of economics and business education have focused on student learning. However, there is little empirical work on the effects of higher grading standards. Bonesrønning $(1999,2004)$ and Figlio and Lucas (2004) reveal that students increase the study effort when they are exposed to harder grading standards. Swinton (2010) shows that assigning two grades in a course, one "knowledge" grade that explicitly rewards content learning, and one "effort" grade measuring student effort, there is a strong correlation between them and a strong effort - knowledge relation. Betts and Grogger (2003) report an increased educational achievement for students near the top of the test score distribution. Chulkov (2006) provides evidence on the response of various student types to the use of simple grading incentives, and that this response is not uniform. Empirical analyses seem to reveal that the strictness of grading standards affects performance. As far as we know no empirical study does consider how grading standards affect attitudes to study effort when taking into account both gender and personality distinctions among students.

Grading is introduced as an instrument to influence the student's choice and reduce the input substitutions due to reallocation of the student's time. Theoretical models for student achievement usually assume that students allocate time rationally to maximize their utility (Bacdayan 1997). Empirical studies have to involve student's preferences to reveal or predict their time allocation. Actually, higher grading standards may lead to a response of decreased study effort among students and more time spent on non-academic activities (substitution effect), or it may lead to increased study effort (complementary effect). Both gender and personality distinctions among students may count for these different responses and, therefore, it is important to explore these relationships. The student's preferences should explicitly be taken into account, as it can predict a response from change in grading practice. However, the few studies of student responses to the grading practice have not focused explicitly on personality distinctions among students.

Generally, student's preferences are taken into account in a simple way by assuming either a uniform utility function or by using different utility functions. Guest (2001) presents a model which includes a different student academic orientation, which is labelled "active" learners and «passive» learners, when he is studying an optimal mix of teaching methods. The impact of the traditional lecture-exam versus active learning based on the 
assessment of student performance of class participation, are explored by Peters (2008). His study reveals that different student preferences affect the amount of time dedicated to reading and study. The present study is also focusing on student study effort response. However, this study explores how higher grading standards will affect time devoted to learning activities when personality temperament to reveal a broader range of student preferences is considered.

The scope of this study explores the relationship between grading practice, gender, student personality distinctions and attitudes towards effort response. The main issue is to introduce explicitly student personality distinctions and, hence, reveal how these different preferences affect the response to a higher grading practice. There is a voluminous amount of research into how personality types affect learning in general, and even in economics and business courses as well (Borg \& Shapiro, 1996; Borg \& Stranahan, 2002a, 2002b; Fallan, 2006; Opstad \& Fallan, 2010; Ziegert, 2000), but so far no studies of how these differences affect the outcome of changes in grading practice.

Most studies of students learning economics and business use the Myers-Briggs Type Indicator (MBTI) to evaluate the effect of personality types on educational outcome. The present study adopts this type of indicator, because it uses a person's preferences rather than clinical diagnosis to indicate personality type (Benfari \& Knox, 1991). The MBTI reveals personality distinctions that suggest that one is either extrovert (E) or introvert (I), how they simply receive and process information as being either a sensing $(\mathrm{S})$ or an intuitive $(\mathrm{N})$ person, how they prefer to judge and evaluate information, being either a thinking $(\mathrm{T})$ or a feeling $(\mathrm{F})$ person, and whether their dominant function or lifestyle orientation have either a judging $(\mathrm{J})$ or a perceiving $(\mathrm{P})$ orientation, when dealing with the outer world (Briggs \& Myers, 1998; Lawrence, 1993). Despite of psychometric limitations and criticisms of the MBTI (Pittenger, 2005) the value of personality assessment is widely used to reveal preferences. Hence, we are able to explore whether these differences in preferences affect student attitude towards effort response to perceived harder grading practice. The review of empirical research indicates a strong attitude behaviour relation and reveals attitudes being strongly correlated with future behaviour (Ajzen \& Fishbein, 1977; Glasman \& Albarracín, 2006).

The paper is organized as follows. The next section clarifies the distinctions of preferences based on the MBTI. The following section includes sample, data and the research methodology, and then the empirical model is explained. Thereafter, the findings are reported, conclusions are drawn and, finally, some implications are indicated.

\subsection{Personality Distinctions and Preferences}

The MBTI reveals a person's preferences according to the four distinctions mentioned above (Myers, 1980). It is based on the personality theory by the Swiss psychologist C.G. Jung, who first presented the theory in his treatise Psychological Types in 1920.

The personality distinctions are measured through a series of items in the MBTI (Briggs and Myers, 1998; Lawrence, 1993). The individual is asked to distinguish between dichotomous choices of phrases, designed to reveal his or her preferences in the four mental processes included in the MBTI. The series of items will make the individual reveal his or her mental processes, being mainly extrovert (E) or introvert (I), being a thinking (T) or a feeling (F) person in his or her judging process, or whether we are dealing with a sensing (S) or intuitive (N) person in his or her perceiving process. Likewise, judgement $(\mathrm{J})$ does not combine with perception $(\mathrm{P})$, because one of them will dominate. According to the MBTI, these mental processes in pairs are seen as polarities.

Extroversion and introversion are innate and inherited attitudes that unfold regardless of environmental influences. Although everyone must be outward-turned in order to act, as well as inwards-turning, in order to reflect on their action. However, according to one's preferences one of these attitudes will dominate. Extroverts (E) prefer action, whereas introverts (I) prefer reflection.

The next personality distinction is the mental process of sensing $(\mathrm{S})$ versus intuition $(\mathrm{N})$. It refers to a person's preferred way of acquiring information about the world. A sensing person prefers learning by a sequential, step by step approach to new material, starting with familiar, solid facts, moving gradually toward abstract concepts and principles, and distilling these concepts and principles based on their own personal, concrete experience. These individuals focus on details and have a practical and present orientation. Intuitive persons like the big picture, and focus on patterns, rather then the details. An intuitive person prefers learning by following inspiration, jumping into new material to pursue an intriguing concept, finding their own way through new material, attending to details only after the big picture is clear, reading and exploring new skills. No one uses only one of these mental processes alone, but one of them is more fully developed. Hence, a person is categorized as being either sensing or intuitive. This is based on which of the two mental processes that is the 
most developed in the person.

The third distinction is the mental process that determines how people prefer to make judgements. The person judges information in one of these two ways: thinking or feeling. Thinking $(\mathrm{T})$ is decision-making based on principled reasoning, logic, and impersonal analysis to evaluate information and situations. To make a judgement, the criteria used are sufficiency of data, validity, and reasonableness. The thinking type prefers learning by having objective material to study, avoiding emotional issues to get clear thinking, analyzing problems to bring logical order out of confusion, and getting a sense of mastery. Feeling $(\mathrm{F})$ by contrast, uses empathy and personal values to make a judgement. Of prime importance in feeling is the impact a judgement will have upon another person. The feeling person calculates subjectively whether a judgement is important or unimportant, valuable or useless. The feeling person prefers learning by personal relationships rather than impersonal individualized activities, helping and responding to other people's needs, and choosing topics to study that they care deeply about. Although every person may use both these ways of making judgments, only one of them will dominate. Thinkers use the thinking process more often, and it becomes more fully developed. The opposite is true for feeling persons.

The fourth distinction is an 'orientation' variable that helps to clarify which is a person's dominant function. This distinction is introduced to indicate which kind of function - judging $(\mathrm{J})$ or perceiving $(\mathrm{P})$ - a person mostly uses in dealing with the outer world. A judging person prefers order and structure, wanting to know exactly what they are accountable for and by what standards they will be judged, treating assignments as serious business, and persisting in doing them. He or she is goal-orientated and have detailed plans for reaching the goals. But this person is often anxious until a decision is made. Perceiving students are spontaneous and prefer a flexible environment. They prefer learning by spontaneously following their curiosity, studying to discover something new to them, and finding novel ways to do routine assignments, so as to spark enough interest to do the assignments. In the end, each individual's preferences will decide who is a judging or a perceiving person.

Table 1. The four polarities describing a person's personality type

\section{E: Extroversion}

The person's interest flows mainly to the outer world of actions, objects, and persons.

\section{S: Sensing}

The person prefers to perceive the immediate, real, practical facts of experience and life.

\section{T: Thinking}

The person prefers to make judgments and decisions objectively, impersonally, considering causes of events and where decisions may lead.

\section{J: Judgment}

The person prefers mostly to live in a decisive, planned, and orderly way, aiming to regulate and control events.

\section{I: Introversion}

The person's interest flows mainly to the inner world of concepts and ideas.

\section{N: Intuition}

The person prefers to perceive the possibilities, relationships, and meanings of experiences.

\section{F: Feeling}

The person prefers to make judgments and decisions subjectively and personally, weighing values of choices and how they matter to others.

\section{P: Perception}

The person prefers mostly to live in a spontaneous, flexible way, aiming to understand life and adapt to it.

Source: Lawrence (1993).

\section{Method}

\subsection{Sample}

Our sample includes 150 students at a Scandinavian business school. The sample was not chosen at random. In fact, the sample comprised students in two compulsory classes in 2005 and 2006, respectively, in their second year at the business school. No optional subjects were offered in the first year of their business education. Therefore, these students had taken the same compulsory subjects and, consequently, should have almost identical background knowledge of business subjects.

The sample contains only those students who attended the last lecture before the final exam, and who voluntary answered a questionnaire. Most students attended this last lecture, and very few of them refused to participate in 
the study. Actually, the sample only contains students who (1) participated in the last lecture and (2) were willing to participate.

\subsection{Questionnaire}

The questionnaire ${ }^{2}$ is based on MBTI to reveal which of the personality distinctions they belonged to. The students answered questions concerning how many of the classroom lectures in all subjects they had participated in and how much out of class study time per week they had spent. Furthermore, the participating students provided their student identification number, allowing us to find their admittance GPA.

The dependent variable of student attitude towards effort response to a harder grading practice is included in the questionnaire. The students should express whether they agree that a hard grading practice increase their study effort by a 5-point likert scale, from "fully agree" to "fully disagree". This should be a suitable proxy for effort response since reviews of empirical research have revealed a strong attitude - behaviour relation (Ajzen \& Fishbein, 1977; Glasman \& Albarracín, 2006).

The empirical model is based on a standard education production model. Student ability, study effort and gender, in addition to student MBTI preferences, are included in the model.

The proxy for student ability is the grade point average (GPA) from high school. In the Scandinavian school system we have nothing like Student Admittance Test (SAT). GPA is the competing factor in business schools that have restricted admission. The applicants are ranked by a grade scale in each subject from high school, where 6 is best and 1 is the lowest score. GPA is the grade point average multiplied by 10, and applicants with advanced exam courses in high school will have extra points included.

Student effort devoted to learning has been interpreted in different ways and with mixed results in the educational production function (Parker, 2006). Attendance at lectures is commonly used as proxy for student effort. In this study we adopt (1) total effort, which includes the number of hours attended at lectures and out of class study time, and (2) out of class study time, as an alternative measure of hours used at homework. The number of hours per week of lecturing can have values from 0 to around 30, depending on which subject the student has chosen. The compulsory courses offer lectures of about 15 hours a week. By including the amount of hours of students' work besides the lectures, we can register the total number of weekly hours of academic work in all courses. Correa and Gruver (1987) define effort as the time allocated to activities related to education, which is consistent with total effort above.

The MBTI is measured by dichotomous (dummy) variables indicating the dominant preference. Fallan (2006) found that extrovert, sensing, thinking, and judging students were majority groups among students in a Scandinavian business school with restricted admission.

Table 2. Measurement of variables (descriptive statistics for the sample: N, mean (standard deviation) and percentage for dichotomous variables)

\begin{tabular}{|c|c|c|}
\hline Variable & Measurement of variables & Mean (SD) /Percentage \\
\hline $\begin{array}{l}\text { Harder grading practice will increase } \\
\text { my study effort }\end{array}$ & $\begin{array}{l}\text { Grade scale from } 1 \text { to } 5 \text { where } 5 \text { means } \\
\text { fully agree and } 1 \text { fully disagree. }\end{array}$ & $3.84(1.07)$ \\
\hline Ability $=$ GPA from high school & $\begin{array}{l}\text { Grade scale from best to worst: } 6,5,4,3 \text {, } \\
2,1 \text {. GPA is multiplied with } 10 \text { and } \\
\text { special points are added. }\end{array}$ & $51.04(4.08)$ \\
\hline Total effort & $\begin{array}{l}\text { Participating in classes and out of class } \\
\text { study time, average hours a week }\end{array}$ & $26.99(10.6)$ \\
\hline Out of class effort & $\begin{array}{l}\text { Out of class study time, average hours a } \\
\text { week }\end{array}$ & $13,97(8,93)$ \\
\hline Gender & $\mathrm{F}=0, \mathrm{M}=1$ & $0.47(0.5)$ \\
\hline \multicolumn{3}{|l|}{ MBTI preferences: } \\
\hline Extraversion vs Introversion & Extraversion 1, Introversion 0 & $\mathrm{E}=84 \%, \mathrm{I}=16 \%$ \\
\hline Sensing vs Intuitive & Sensing 1 , Intuitive 0 & $\mathrm{~S}=79 \%, \mathrm{~N}=21 \%$ \\
\hline Thinking vs Feeling & Thinking 1 , Feeling 0 & $\mathrm{~T}=89 \%, \mathrm{~F}=11 \%$ \\
\hline Judging vs Perceiving & Judging 1 , Perceiving 0 & $\mathrm{~J}=87 \%, \mathrm{P}=13 \%$ \\
\hline
\end{tabular}


Note. This research project includes personality data which requires a license from the National Data Inspectorate. The questionnaire meets the requirements from the National Social Science Data Service (NSD) as the Privacy Ombudsman for all the national universities according to the Personal Data Act.

\subsection{The models}

An ordered probit model is adopted, because the dependent variable is ordinal and discrete. The ordered probit estimation technique is appropriate in studies of economic education research, where the dependent variable is either on a likert scale or a discrete course grade variable (see e.g., Becker, 1983; Borg et al., 1989).

Two different empirical models are tested:

1) Grading practice response $=f$ (Ability, Total effort, Gender, MBTI)

2) Grading practice response $=f$ (Out of class effort, Gender, MBTI)

According to the standard education production model, the response to a harder grading practice will depend on the student's initial effort and ability, and according to Bonesrønning (2004), grading practice response might be affected by gender. Hence, Model 1 includes these variables together with MBTI preferences. Model 2 drops Ability and Total effort and includes a more sensitive effort measure, "Out of class effort".

These two models are highlighting the exploration of how grading practice response is affected by the student's personality distinctions. Higher grading standards might stimulate some personality distinctions of students to spend more time on their studies. For other personality distinctions of students, the effect might be the opposite. Some personality distinctions among students might find it so hard to improve and get a better grade that they prefer to give other subjects or non-academic activities higher priority. Our hypothesis is that student attitude to higher grading standards is affected by their MBTI preferences.

\section{Estimated Results of Grading Practice and Student Effort Response}

The results from the ordered probit analyses estimated with a maximum likelihood estimation technique are presented in Table 3. The table shows the estimated regression coefficients, with the standard error in parentheses. Previous research provides a priori expectations about some of the signs of the predicted coefficients, but not for all. Therefore, a two-tailed test of significance is conducted, with a null hypothesis of no predicted relationship between the dependent and independent variables.

Table 3. Ordered probit regressions dependent variable: Hard grading increase the students' effort Estimated coefficient, standard error in parentheses and $z$-score

\begin{tabular}{|c|c|c|c|c|}
\hline \multirow{2}{*}{$\begin{array}{l}\text { Independent } \\
\text { variable }\end{array}$} & \multicolumn{2}{|c|}{ (Model 1) } & \multicolumn{2}{|c|}{ (Model 2) } \\
\hline & $\begin{array}{l}\text { Coef. } \\
\text { (std.err.) }\end{array}$ & (z) & $\begin{array}{l}\text { Coef. } \\
\text { (std.err.) }\end{array}$ & (z) \\
\hline \multirow[t]{2}{*}{ Constant } & 0.78 & $3.43 * * *$ & 0.82 & $3.59 * * *$ \\
\hline & $(0.23)$ & & $(0.23)$ & \\
\hline \multirow[t]{2}{*}{ GPA } & -0.0093 & -0.38 & & \\
\hline & $(0.025)$ & & & \\
\hline \multirow[t]{2}{*}{ TOTAL EFFORT } & 0.107 & 1.29 & & \\
\hline & $(0.008)$ & & & \\
\hline \multirow{2}{*}{$\begin{array}{l}\text { OUT OF CLASS } \\
\text { EFFORT }\end{array}$} & & & 0.24 & $2.37 * *$ \\
\hline & & & $(0.10)$ & \\
\hline \multirow[t]{2}{*}{ GENDER } & 0.32 & $1.68^{* *}$ & 0.38 & $2.02 * *$ \\
\hline & $(0.19)$ & & $(0.19)$ & \\
\hline \multirow{2}{*}{$\begin{array}{l}\text { EXTRAVERSION vs } \\
\text { INTROVERSION }\end{array}$} & 0.318 & 1.28 & 0.39 & $1.69^{*}$ \\
\hline & $(0.25)$ & & $(0.22)$ & \\
\hline \multirow{2}{*}{$\begin{array}{l}\text { SENSING vs } \\
\text { INTUITION }\end{array}$} & -0.127 & -0.54 & -0.18 & -0.81 \\
\hline & $(0.23)$ & & $(0.22)$ & \\
\hline
\end{tabular}




\begin{tabular}{lllll}
\hline THINKING vs & 0.71 & $2.74 * * *$ & 0.79 & $3.10^{* * *}$ \\
FEELING & $(0.26)$ & & $(0.25)$ & $3.17^{* * *}$ \\
JUDGING vs & 0.80 & $2.92 * * *$ & 0.85 & \\
PERCEIVING & $(0.27)$ & & $(0.27)$ & \\
Chi-square & $23.80 * * *$ & & $31.06^{* * *}$ & 150 \\
$\mathrm{~N}$ & 141 & & & \\
\hline
\end{tabular}

Significance level: $* \mathrm{p}<.10 ; * * \mathrm{p}<.05 ; * * * \mathrm{p}<.01$

Model 1 reveals that male students will significantly increase their study effort in response to higher grading standards, compared with their female peers. Furthermore, two of the personality distinctions are relevant for a complementary study effort response. Thinking students will respond to a harder grading practice by increasing their study effort compared with their feeling counterparts, and also students who have a dominant judging orientation before a perceiving orientation will significantly increase their study effort. Neither the reduced study response to a harder grading practice from ability and a sensing personality distinction nor the positive study response from total effort and an extravert personality distinction are significant responses.

Student ability and total effort are excluded from Model 2. Out of class effort is adopted instead of total effort, because it is a more sensitive measure of time devoted to work outside the class. The grading system response is more dependent on the initial level of out of class study time than the total study effort, which also includes participation in class lectures. Students with a high initial level of out of class effort will significantly increase their study efforts, in response to higher grading standards, and so do male students compared to their female peers. Three personality distinctions reveal a significant increase in study effort in response to harder grading practice in Model 2. Extroverts are more likely to increase effort than their introvert counterparts, thinking versus feeling students, and judging oriented students versus perceiving.

\section{Discussion}

Previous research has revealed that students' initial ability is positively related to better exam scores, when a standard education production model with personality distinctions are adopted (Borg \& Shapiro, 1996; Borg \& Stranahan, 2002; Opstad \& Fallan, 2010). Actually, high ability students have experienced success and may perceive themselves to be at the top grade level already. If they have set grade targets, these students will more likely minimize their effort to obtain the target grade level, even if higher grading standards are introduced (Allgood, 2001). Their marginal utility from more time spent on studying will be low, or even negative, if they perceive the target grade level to be obtained already and, hence, lower than the marginal utility from more time spent on leisure or other non-academic activities. However, this effect could be counteracted using a rank-order grading system (Cherry \& Ellis, 2005).

The middle and low ability students may react differently to higher grading standards. Most students in these groups will probably increase the study effort in response to a harder grading practice (Becker \& Rosen, 1992; Schmidt, 1983). Some low ability students may give up when they are confronted with higher grading standards. Actually, low ability students are not part of this sample, because the restricted admission to the business school requires a high GPA from high school. The present negative sign of the z-score from GPA in Model 1 may indicate the above relation. However, we do not find any significant response. Gender and personality distinctions may have diluted the response.

Students' study effort is an important variable in theoretical education production models (Needham, 1978; Correa \& Gruver, 1987), as it explains academic achievement. Hence, the initial study effort should affect harder grading response in either a positive or a negative way. When perceiving the grading system to be tougher, some students will devote more time to studies, while others might find it so difficult to maintain their expected grade level or improve it that they give other non-academic activities higher priority. Raising the grading standards may stimulate a student to increase the effort only when the expected marginal rate of return to study effort is positive. When the initial study effort is high, the diminishing marginal rate of return might cause the expected marginal rate of return on effort to be negative. When this critical point is reached, a further raise in perceived grading standards might cause the students to work less (Becker \& Rosen, 1992).

We find no significant effect of initial total effort on grading practice response, but there is a significant and positive effect from out of class effort. Students, who initially have the highest out of class effort, will work harder when grading practice gets tougher. Why is this so? Shouldn't we expect a negative rate of return to study 
effort for those students who initially devote most time to out of class work? The result from the present study reveals that the total average time devoted to academic activities is only 27 hours a week ( $S D=10.6)$, including average time devoted to out of class work of 14 hours a week $(\mathrm{SD}=8.9)$. This is a modest level of academic work compared with working life overall. In this setting most students will expect a positive rate of return to out of class work. Hence, a harder grading practice will be an appropriate instrument, all other things being equal.

Betts and Grogger (2003) find that higher grading standards increase academic achievement, but that the increase is greatest for the best achieving students. The best achieving students are those who work hardest on academic activities (Opstad \& Fallan, 2010). The present findings should be interpreted as support for the results by Betts and Grogger (2003).

The increase of study effort from the students that already devote more time to out of class work than their peers will widen the gap between these groups of students. The gap in working hours among students might give greater inequalities in the distribution of the students' achievements. This supports the findings by Bonnesrønning (1999) and Betts and Grogger (2003). Hence, implementing higher grading standards will have both winners and losers. Increased drop out rates could be one possible effect.

The present study reveals different study responses to a harder grading practice between male and female students. Male students will increase their study effort significantly in response to perceived higher grading standards, compared with their female peers. Male students are willing to increase time devoted to studying, if a change in grading practice requires more to get an expected grade. On the other hand, female students are less sensitive to changes in grading standards. The present results support equivalent results from a previous study (Bonesrønning, 2004). However, we should emphasize that these results are based on self-reported preferences and self-reported view on their own abilities. This might give a gender bias. Since business schools in Scandinavia today often have just as many female students as males, the proportion of females should be considered before implementing higher grading standards.

Correa and Gruver (1987) have pointed out that the interaction between harder grading and student response depends on characteristics of the student's preferences. The present study reveals that the self-reported personal preferences and, hence, personality distinctions, do have a significant effect on student response to harder grading. The response is substantial and most significant for thinking $(\mathrm{T})$ versus feeling $(\mathrm{F})$ students. "Thinking" students prefer principled reasoning, logic, and impersonal analysis to evaluate information and situations. This student will significantly increase the study effort in response to harder grading than will the "feeling" counterpart (Table 3). "Thinking" students are the most common personality group in business schools. Students with a "feeling" personality distinction have an opposite way of judging information. "Feeling" students is a minority group in business schools. Therefore, harder grading will be an appropriate instrument for the majority group of "thinking" students, but less appropriate for "feeling" students.

This study reveals a strong and significant effect from the self-reported judging $(\mathrm{J})$ personality orientation versus perceiving (P) oriented students. "Judging" students are those who prefer order and structure, to know exactly what they are accountable for, by what standards they will be judged, treating assignments as serious business, and persisting in doing them. "Judging" students belong to a considerable group in business schools compared to the "perceiving" students. These students respond to harder grading by significantly allocating more time to academic activities than their "perceiving" counterparts. Harder grading practice will positively trigger the considerable group of "judging" students. These students know that they have to work harder even to maintain their grades. Students, who have a perceiving personality orientation are spontaneous and flexible and may not be so goal oriented as their "judging" counterparts. Higher grading standards may be less appropriate for "perceiving" students.

Furthermore, the study shows that extrovert (E) students respond better to harder grading than their introvert (I) counterparts. Only Model 2 reveals a significantly increased study effort for "extrovert" students, compared to their "introvert" peers. The sample of students counts mostly extroverted personality distinctions. Hence, implementing harder grading is most appropriate for this group and less for the group of introverts.

The distinction between sensing $(\mathrm{S})$ personality and intuitive $(\mathrm{N})$ personality seems to be irrelevant for responses to harder grading. Sensing students do respond with less study effort than intuitive students $(\mathrm{N})$, but this is not a significant effect.

These results are based on self-reported preferences, personality characteristics, effort and attitudes towards harder grading while GPA is based on the admittance register. Can the effects of a harder grading practice be inferred from a questionnaire based study? Can we rely on self-reporting? When it comes to personal preferences and personality distinctions there is no better source of information than the student's own answers. But can we 
infer increased study effort from self-reported attitudes towards harder grading practice? Many reviews of empirical research (Ajzen \& Fishbein, 1977; Glasman \& Albarracín, 2006) support the contention of a strong attitude-behaviour relation and that attitudes are strongly correlated with a future behaviour. Therefore, self-reported attitudes should be a suitable proxy for actual behaviour response.

\section{Conclusion}

The main contribution of this study is to explore how gender and the MBTI personality distinctions the affect grading practice response. Grading practice is a political instrument to make students allocate more time to learning activities. However, a tougher grading system may affect the time devoted to academic activities differently, depending on gender and the student's personality distinctions. The present study recommends higher grading standards for male students, students who have a high initial level of out of class work, but still have time to slack, compared with time devoted to work in working life in general, students who have a thinking personality rather than a feeling distinction, students who have a judging rather than a perceiving orientation, and students who are more extroverted rather than introverted. However, each class and each school should have a uniform grading system. Hence, the composition of the class has to be taken into account when a modification of the grading practice is considered. Modifications of a grading practice may produce both winners and losers.

The present sample of economics and business students is comprised of a majority of students who belong to a "thinking" personality rather than to a "feeling" distinction, to a "judging" rather than to a "perceiving" orientation, and to an "extroverted" rather than to an "introverted" personality. In this setting, a change toward a harder grading practice may affect students to increase their study effort overall.

Future research is needed to see whether these findings are readily generalized, or whether they only should be interpreted in light of Scandinavian culture and business school settings.

\section{References}

Ajzen, I., \& Fishbein, M. (1977). Attitude-Behavior Relations: A Theoretical Analysis and Review of Empirical Research. Psychological Bulletin, 84(5), 888-918. http://dx.doi.org/10.1037/0033-2909.84.5.888

Anderson, B., Benjamin, H., \& Fuss, M. A. (1994). The determinants of success in university introductory economics courses. Journal of Economic Education, 2(2), 99-119. http://dx.doi.org/10.2307/1183277

Allgood, S. (2001). Grade targets and teaching innovation. Economics of Educational Review, 20(5), 483-495. http://dx.doi.org/10.1016/S0272-7757(00)00019-4

Bacdayan, A. W. (1997). A mathematical analysis of the learning production process and a model for determining what matters in education. Economics of Educational Review, 16(1), 25-37. http://dx.doi.org/10.1016/S0272-7757(96)00003-9

Becker, W. E. Jr. (1983). Economic education research: Part III, statistical estimation methods. Journal of Economic Education, 14, 4-15. http://dx.doi.org/10.2307/1182852

Becker, W., \& Rosen, S. (1992). The learning effect of assessment and evaluation in high school. Economics of Education Review, 11(2), 107-118. http://dx.doi.org/10.1016/0272-7757(92)90002-K

Betts, J. R., \& Grogger, J. (2003). The impact of grading standards on student achievement, educational attainment and entry -level earnings. Economics of Education Review, 22, 343-352. http://dx.doi.org/10.1016/S0272-7757(02)00059-6

Bonesrønning, H. (1999). The variation in teachers' grading practices: causes and consequences. Economics of Education Review, 18(1), 89-105. http://dx.doi.org/10.1016/S0272-7757(98)00012-0

Bonesrønning, H. (2004). Do the Teachers' Grading Practices Affect Student Achievement? Education Economics, 12(2), 152-167.

Borg, M. O., Mason, P. M., \& Shapiro, S. L. (1989). The Case of Effort Variables in Student Performance. Journal of Economic Education, 20(3), 308-313. http://dx.doi.org/10.2307/1182307

Borg, M. O., \& Shapiro, S. L. (1996). Personality Type and Student Performance in Principles of Economics. Journal of Economic Education, 27(1), 3-25. http://dx.doi.org/10.2307/1183005

Borg, M. O., \& Stranahan, H. (2002). The effect of gender and race on students performance in principles of economics: the importance of personality type. Applied Economics, 34, 589-598. http://dx.doi.org/10.1080/00036840110039249

Briggs, K. C., \& Myers, I. B. (1998). Myers-Briggs Type Indicator. Palo Alto, CA: Consulting Psychologists 
Press.

Cherry, T. L., \& Ellis, L. V. (2005). Does Rank-Order Grading Improve Student Performance? Evidence from a Classroom Experiment. International Review of Economics Education, 4(1), 9-19.

Chulkov, D. V. (2006). Student Response to Grading Incentives: Evidence from College Economics Courses. Journal of Instructional Psychology, 33(3), 206-211.

Correa, H., \& Gruver, G. W. (1987). Teacher- student interaction: A game theoretic extension of the economic theory of education. Mathematical Social Sciences, 13, 19.47. http://dx.doi.org/10.1016/0165-4896(87)90057-6

Fallan, L. (2006). Quality Reform: Personality Type, Preferred Learning Style and Majors in a Business School. Quality in Higher Education, 12(2), 193-206. http://dx.doi.org/10.1080/13538320600916817

Figlio, D. N., \& Lucas, M. E. (2004). Do high grading standards affect student performance? Journal of Public Economics, 88, 1815-1834. http://dx.doi.org/10.1016/S0047-2727(03)00039-2

Glasman, L. R., \& Albarracín, D. (2006). Forming Attitudes That Predict Future Behavior: A Meta-Analysis of the Attitude-Behavior Relation. Psychological Bulletin, 132(5), 778-822. http://dx.doi.org/10.1037/0033-2909.132.5.778

Guest, R. (2001). The Instructor's Optimal Mix of Teaching Methods. Education Economics, 9(3), $313-326$. http://dx.doi.org/10.1080/09645290110086162

Lawrence, G. D. (1982). People types and tiger stripes: A practical guide to learning styles (2nd ed.). Gainsville, Fla.: Center for Application of Personality Types.

Lawrence, G. D. (1993). People types and tiger stripes: A practical guide to learning styles (3rd ed.). Gainsville, Fla.: Center for Application of Personality Types.

Myers, I. B. (1980). Introduction to type. Palo Alto, CA: Consulting Psychologists Press Inc.

Needham, D. (1978). Student Effort, Learning and Course Evaluation. Journal of Economic Education, 10(1), 35-43. http://dx.doi.org/10.2307/1182164

Opstad, L., \& Fallan, L. (2010). Student Performance in Principles of Macroeconomics: The Importance of Gender and Personality Type. International Review of Economics Education, 9(1), 76-92.

Parker, K. (2006). The effect of student characteristics on achievement in introductory microeconomics in South Africa. South African Journal of Economics, $137-149$. http://dx.doi.org/10.1111/j.1813-6982.2006.00054.x

Peters, R. (2008). Facilitating Interaction to Promote Learning. The International Journal of Learning, 15(7), 159-166.

Pittenger, D. J. (2005). Cautionary Comments Regarding the Myers-Briggs Type Indicator. Consulting Psychology Journal: Practice and Research, 57(3), 210-221. http://dx.doi.org/10.1037/1065-9293.57.3.210

Schmidt, R. M. (1983). Who maximizes what? A study in student time allocation. American Economic Review, 72(2), 23-28.

Swinton, O. H. (2010). The effect of effort grading on learning. Economics of Education Review, 29(6), 1176-1182. http://dx.doi.org/10.1016/j.econedurev.2010.06.014

Ziegert, A. J. (2000). The role of personality temperament and student learning in principles of economics: Further evidence. Journal of Economic Education, 31(4), 307-322. 